\title{
Expatriates' Psychological Distress Components of Malaysian Construction Company in Host Country
}

\author{
Halmi Zainol ${ }^{1}$, Abdul Malek A Tambi², Nor Eeda Ali ${ }^{1}$, Hazirah Azami ${ }^{1}$ \\ ${ }^{1}$ Faculty of Architecture Planning and Surveying, Universiti Teknologi MARA, Perak Branch, Malaysia \\ ${ }^{2}$ Faculty of Business and Management, Universiti Sultan Zainal Abidin, Terengganu, Malaysia
}

halmizainol@gmail.com, malekahmad@unisza.edu.my, noree038@uitm.edu.my, hazirahazami1@gmail.com Tel: +6019-5582282

\begin{abstract}
Psychological distress is pertaining to anything leads to human well-being and satisfaction of the individual. Individual adjustment is a degree of psychological distress that an expatriate faces during an assignment in the host country. Unhappiness with the organisation will contribute to leaving for a prospective employer. Psychological influences such as interaction, reward and, social life contribute to the success of the expatriate. Content analysis was used in the study. The study aimed to determine the factors which led to expatriate's physiological distress. The study had found that there was a need for psychological adjustment while working in the host country.
\end{abstract}

Keywords: Psychological distress; Expatriate; Construction

eISSN: 2398-4287@ 2020. The Authors. Published for AMER ABRA CE-Bs by e-International Publishing House, Ltd., UK. This is an open-access article under the CC BYNC-ND license (http://creativecommons.org/licenses/by-nc-nd/4.0/). Peer-review under responsibility of AMER (Association of Malaysian Environment-Behaviour Researchers), ABRA (Association of Behavioural Researchers on Asians) and cE-Bs (Centre for Environment-Behaviour Studies), Faculty of Architecture, Planning \& Surveying, Universiti Teknologi MARA, Malaysia.

DOI: https://doi.org/10.21834/ebpj.v5i14.2233

\subsection{Introduction}

Malaysia's number of multinational construction companies has increased from year to year. The rapid growth of Malaysia's economy, as well as globalisation, allowed Malaysian companies to operate overseas (Zainol \& Aziz, 2010). Spectacular socio-economic development has taken place all around, and thriving construction industries are apparent everywhere in the country. Construction is a high employment source in any country. The primary role of an expatriate manager can be thought of as a catalyst that ensures the continuity of retaining expatriates an organisation.

The statistics on Malaysian expatriates working abroad is growing from year to year. It was estimated in 2019, that approximately 150,000 Malaysians who were working in the US, Australia, Canada and the UK were highly skilled. In line with the Fourth Industry Revolution, the construction industry showed that Malaysian firms were getting more involved in construction projects abroad (Zainol, Isa, Alauddin \& Derus, 2016). Expatriates in Malaysia with more significant conscientiousness personality fared better in their task and contextual performance. Nevertheless, Malaysian expatriates who are working abroad, and are peculiarly Malaysian, face the burden of cross-cultural adjustment. As a consequence, the feeling of unsatisfactory adjustment leads to poor individual performance resulting from "cross-border assignments". The main aspect that leads to the failure of Malaysian expatriates in their assignments was the difficulty they faced in adapting to a new environment (Zainol et al., 2016).

The purpose of the study was to identify the elements that contributed to the psychological distress of Malaysian expatriates on assignment with Malaysian companies abroad. Researchers had examined various concepts to provide meaning to the psychological comfort phenomenon. Pinto et al. (2017) found that psychological comfort was synonymous with the concept of well-being and quality of life. Halim, Bakar, and Mohamad (2019) stated that comfort was related to everything contributing to the well-being and convenience of the aspects of life and improvement of living conditions in inhabited space. Thus, expatriate's psychological distress regarding various

eISSN: 2398-4287C 2020. The Authors. Published for AMER ABRA cE-Bs by e-International Publishing House, Ltd., UK. This is an open-access article under the CC BYNC-ND license (http://creativecommons.org/licenses/by-nc-nd/4.0/). Peer-review under responsibility of AMER (Association of Malaysian Environment-Behaviour Researchers), ABRA (Association of Behavioural Researchers on Asians) and cE-Bs (Centre for Environment-Behaviour Studies), Faculty of Architecture, Planning \& Surveying, Universiti Teknologi MARA, Malaysia.

DOI: https://doi.org/10.21834/ebpj.v5i14.2233 
issues of the host culture environment, such as climate, food, healthcare, shopping and housing condition (Froese \& Peltokorpi, 2011). Different interpersonal styles used in the host culture reflected the degree of psychological comfort in the host country (Peltokorpi \& Ramaswami, 2019). Cultural differences between foreign and local values are inevitable in which expatriates experience challenges.

\subsection{Literature review}

Psychological comfort can be thought of as the equivalent of psychological distress. People who sense this negative emotional state would not be able to work efficiently and effectively. On the other hand, people would sense they occupy a quality work environment if it is inclusive and supportive to foreign workers. An expatriate is generally defined as a person with professionals with skills or knowledge and lives or works outside his or her home country. Host country refers to another country where a company runs its business. The company's central headquarters at the home country regularly interacted with host country nationals to coordinate and monitor projects (Fitzpatrick \& Fitzpatrick, 2017). Psychological comfort related to expatriates who lived and worked outside the home country started to learn about the host culture, and make efforts to find successful ways of functioning in a host country (Moran, Harris \& Moran, 2011). They voluntarily pursued employment opportunities abroad and tended to maintain a degree of flexibility and freedom in their interactions, living environment, reward, and social life.

Psychological comfort relates to individual feeling and more complex needs, which are produced by the environment and lifestyle to which the individual has to adapt. Expatriate's psychological comfort concerned various aspects of the host culture environment, such as climate, food, healthcare, shopping, and housing condition (Froese \& Peltokorpi, 2011). According to Stroppa and Spieß, (2011), psychological comfort was characterised by a feeling of satisfaction with a different aspect of life, and a feeling of relative comfort with comparison to others in the reference groups in both the country of origin and the host society.

The study is focusing on the psychological comfort of expatriates that influenced interaction adjustment, living environment, reward, and social life. Expatriates working abroad will not be facing the same cultural atmosphere and working environment such as in Malaysia. Hence, it is essential to examine psychological distress elements that affect expatriates because they have to adapt to the new environment in the host country.

\subsection{Interaction Adjustment}

The interaction was related to the comfort levels when engaging or interacting with host country nationals at work and in nonwork situations (Okpara, 2016). Language ability of expatriates in the host country was positively associated with socio-cultural adjustment (Selmer, \& Lauring, 2011). Interaction adjustment focuses on socialising and speaking with nationals of the host country by way of interacting with host nationals and participating in their social life to improve effectiveness and commitment. The expatriate who has exposure to daily interactions with other expatriates or host nationals will require less cross-cultural adjustment, compared to those who do not interact with each other. The interaction also involves conforming to cultural norms.

Psychological distress reflects personal living and social interaction of an individual. Social interaction adjustment is concerned with the fulfilment of basic needs for services, including entertainment, healthcare, shopping and banking as well as the cost of living associated with the location other than the home country (Zainol et al., 2016). It was also related to an individual's care for their health that requires an awareness of the physical condition, stress reduction and self-responsibility (Pinto et al., 2017). Those behaviours would help expatriates to experience psychological comfort at the I host country. The research had derived the influencing elements of expatriate psychological distress, namely, interaction, living environment, reward, and social interaction. By adopting the model, expatriates could achieve psychological comfort and feel highly motivated while performing their assignment in the host country. The resultant is two-fold; one is increasing in organisational efficiency and effectiveness, and the other is the improvement of quality of life.

\subsection{Living Environment}

The living environment is also an essential element because expatriates try to adjust to the living standard in the host country would lead to other difficulties (Black, 1998). Some expatriates who live in a host country tend to compare the living environment with their home country where it is more comfortable. One of the reasons expatriates refused the offer to work in the host country is that the living standard is different or higher from the home country.

Psychological distress related to living and housing condition (Zainol et al., 2016; Fitzpatrick \& Fitzpatrick, 2019). Health care facilities also influence psychological distress (Vianen, Pater, Kristof-Brown, \& Johnson, 2004). Lin, Robbins \& Lin (2019) stated, religious practices and good interaction with local people are the main elements of psychological distress. Unsatisfactory living conditions or difficulty in getting certain foods may lead affect individual psychological comfort (Caligiuri, Hyland, Joshi \& Bross, 1998; Halim et al., 2019). Living environment elements are the daily basis of expatriates facing during the stay in the host country.

Social interactions and living environment with host country nationals are closely related to one another. When facing a new culture and new situation in the host country, the individual needs to build a new social network with host nationals. Individuals who can accept differences in the host country to become aware of appropriate behaviours (Zainordin, Tan, \& Mei, 2015). Deeper interaction can help bridge the gap between the two cultures, may act as sources of information and assist in the understanding of the host country culture.

\subsection{Reward}

An attractive salary is an incentive for expatriates accepts the assignment. Job satisfaction will be affected if low wages are received and lead to migration to other companies. According to Horwitz (2017), one of the reasons for expatriates to accept international assignments is because of the low salary received in the home country. A study by Rasool, Jundong \& Sohail (2017) found that rewards 
and benefits have a positive relationship with job satisfaction. For example, promotion, salary, fringe benefits and chance to learn new knowledge, skills, and all kinds of benefits are well established among the employees in developed economies.

Rewards and benefits are also affecting the psychological comfort in such manner to enjoy everyday life, support every life and buy the necessities. Expatriates would feel accepted by the organisation after completing the task and achievement towards the organisation. Reward also a part of the basic needs of expatriates, and it seems to influence expatriate's decision to stay or leave the organisation. Besides, for those expatriates are looking more experience and working in the long term should be satisfied with intrinsic rewards such as promotions, recognitions, authority, career development and other intangible benefits.

Psychological distress also related to reward. Expatriation can be a rewarding experience in various ways. Rewards include financial or non-financial rewards, compensation and benefits (Horwitz, 2017). According to Wahab (2014), stated that compensation practices and types of rewards affect their decisions regarding stay in or leave from the organisations. Rewards also have focused on the strength of the link between pay and performance. Besides, financial rewards are often associated with job opportunities and influence the employee to retain in the organisation.

\subsection{Social Life}

Among the components that influence psychological distress is social life. Social life elements of the individual in the host country are food, shopping, banking, cost of living, entertainment and healthcare (Zainol et al., 2016). Shopping and banking are required often of spending activities for people. Moreover, there are also differences in the way people do shopping and food in the home country as compared with the host country. Lin et al., (2019) observed that expatriates need to adjust to shopping because in some host countries bargaining is practised while in their home country bargaining may not be practised. They also found that expatriates would face new things, especially food when they are in their host country. Prior exposures to adjustment of food in the country, expatriates need to be prepared for the changes that they will be facing. This view is supported by (Fisher, 2015) when they agreed that adjustment to food is more crucial compared with adjustment to healthcare, cost of living, and entertainment. However, social life adjustment is also related to engaging socially in any given circumstance and the need for an individual's daily life needs (Fitzpatrick, 2019). Having a social life network was a fundamental factor in adjustment to a new culture in the host country.

Some expatriates in the host country still need this kind of adjustment, especially interaction, living environment, reward and social life for their daily comfort (Lin et al., 2019; Fitzpatrick, 2019). Therefore, when expatriates move to another country, they start to learn about the host culture and make efforts to find successful ways of functioning in a host country. These studies focused on expatriate psychological comfort and explained why expatriates have difficulties adapting to the host country environment.

\subsection{Research Methodology}

The study involved a literature review of past research to identify elements influencing psychological distress and psychological comfort of individuals. Relevant journal articles, proceedings, and books were sought. The literature review was conducted in three stages. The first stage was the identification of elements that influence expatriate adjustment in the host country. The information gathered included definition of terms, theories, components, and related variables were explored. The second stage involved classification of the elements into the psychological comfort of expatriates that contribute expatriate adjustments such as interaction, living environment, reward and social life. The findings from previous studies were identified and screened to suit with the research. Third, the identification conceptual the psychological distress in details relating to interaction, living environment, reward and social life. At this stage, the findings from the previous literature were analysed. A review was able to recapitulate the key elements contributing to psychological distress components. A proposed conceptual model was recommended based on the findings.

\subsection{Discussions and Findings}

Various studies on psychological comfort relating to expatriate adjustments. Limited research regarding Malaysian's expatriate, especially in the construction industry working abroad. The study also shows four elements influenced the psychological distress of expatriates. Psychological distress of Malaysian professional expatriates components is interaction adjustment, living environment, reward and social life. Among interaction adjustment elements are language ability, communication in host country and knowledge. Interaction adjustment with host nationals refers to the degree of psychological comfort regarding different disclosure and interpersonal styles used in the host culture. Living environment elements are living condition such as living condition, housing condition and religious practice. The reward components, including benefits and compensation. Another component influence the psychological distress is social life which includes shopping, banking, cost of living, entertainment \& recreation. Those elements of psychological distress could influence on expatriates.

In psychological distress, interaction, which includes socialising, communication, speaking, and culture is seen as essential to adjustment. Cultural distance or cultural dissimilarity has been another critical factor in predicting adjustment as does linguistic ability, general knowledge about host culture and quality of interaction with the host country. Even though some of these elements may belong to different categories, there are possibilities that the variables can interact with each other to enable successful adjustment. For example, language ability is very much needed for expatriates (or spouse and children) to communicate with the host. Excellent communication skills will ensure that the expatriate can communicate, interact and perform their job satisfactorily, thus enhance his/her adjustment (refer to Fig. 1). In this regard, Vlaj, Caputo, Marzi, \& Dabi (2019) suggested that the organisation should provide language training and social opportunities for expatriates to interact with foreign nationals. 


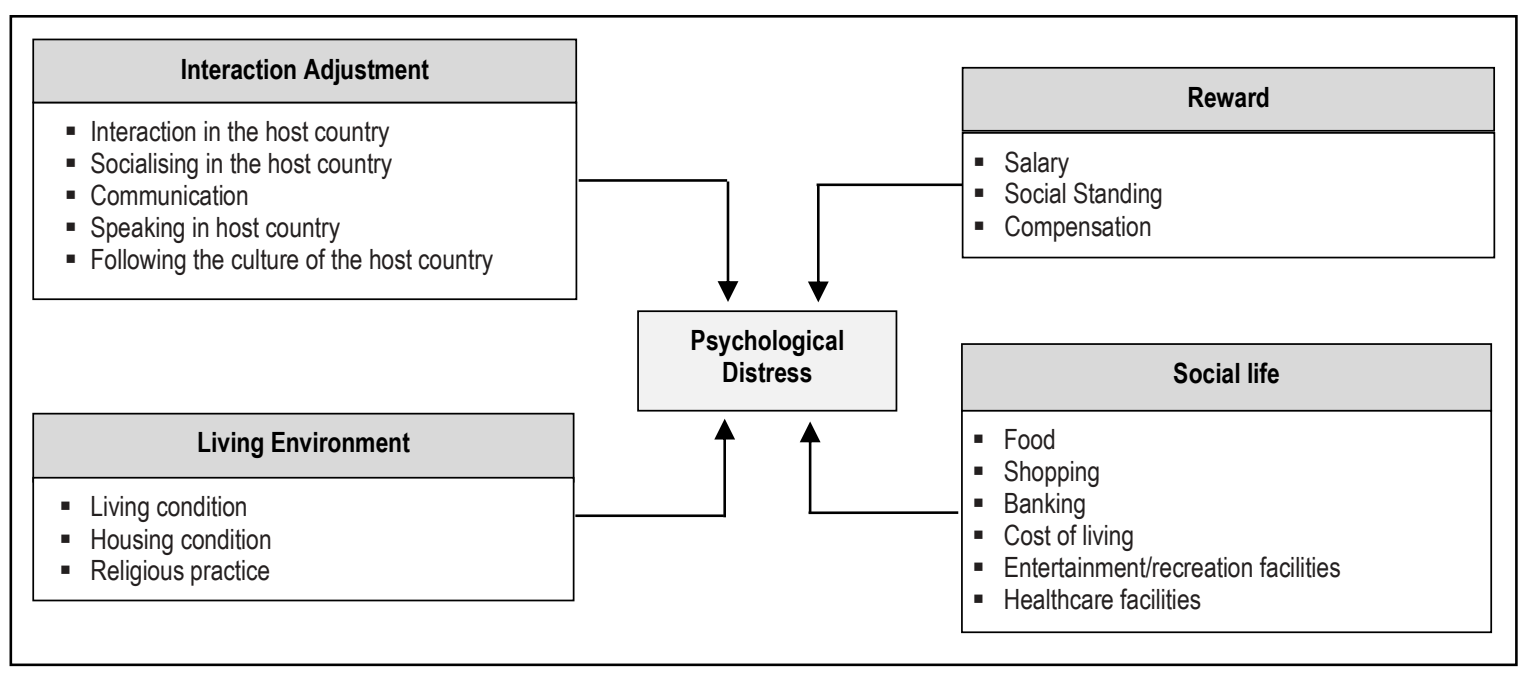

Fig. 1: Psychology Distress Components

Interactions between expatriates and local employees are also emphasised in the concept of expatriate adjustment. It delineates three facets such as general, interactional and work adjustment. While interactional ones 'involves comfortably socialising and interacting with host nationals. Presbitero \& Quita (2017) found that, among other factors, frequent interactions of expatriates with locals as well as their self-efficacy had a positive impact on their adjustment. In contrast, Froese and Peltokorpi (2011) displayed that such interaction affects an expatriate's job satisfaction negatively if the cultural distance between he/she and locals is substantive. Stroppa \& Spieß (2011), suggested that the stress experienced by sojourners is caused by the inability to adjust to the host culture socially. Which primarily results from their lack of social skills needed in dealing with the new situation that an individual might face when dealing with an unfamiliar culture.

Analysis of living environment showed the variables were grouped into three elements, namely, living condition, housing condition and religious practice. The living environment in a host country can cause stress. Expatriates also report living spaces in their home environment and those in the new environment, again causing stress (Barna, 1983). Findings by (Fish \& Fish, 2006; Naithani \& Jha, 2014) showed that adjustment to the living environment is positively correlated with adjustment of expatriates in their host countries. This indicates that adaptation to living environment influences the adjustment of expatriates in their host countries.

Items such as salary, social standing and compensation are the elements influence on expatriate's reward (Tung, 1998). The expatriate salary was the most important in reward. The fact that expatriates are considered one of the most precious resources in an organisation due to high pay and benefits during expatriation. Expatriates salaries are usually considered a salary is higher than that of the local employees due to the following reasons: (i) salary of a candidate selected for an international assignment has to motivate expatriate would agree to go abroad for work and usually high; (ii) expatriates find it more challenging to live in a host country; therefore, living compensation is required which is typically sufficient to pay all taxes without causing a decrease in expatriate real income; (iii) a higher salary is sometimes related to a higher position or rank, which is a stimulus to go to a host country; (iv) salary promotion is also considered as compensation for the inconveniences experienced while abroad especially for different environments, climates, homes and so on.

A study by Rasool et al. (2017) found that rewards and benefits have a positive relationship with job satisfaction. For example, promotion, salary, fringe benefits and chance to learn new knowledge, skills, and all kinds of benefits are well established among the employees in developed economies. Rewards and benefits are also affecting the psychological comfort in such manner to enjoy everyday life, support every life and buy the necessities. Reward also a part of the basic needs of expatriates, and it seems to influence expatriate's decision to stay or leave the organisation. Besides, for those expatriates are looking more experience and working in the long term should be satisfied with intrinsic rewards such as promotions, recognitions, authority, career development and other intangible benefits Rasool et al., (2017). The primary source of support and provide benefits and services of national host company give before arriving and once in the foreign country that will affect the expatriate's quality of life and work abroad. Thus, expatriates feel that welfare is taken care of in the host country.

Social standing represented the second most important (Zainol et al., 2016). Social standing can be considered as close to 'slightly adjusted'. Both aspects, such as salary and social status, also described reasonable satisfaction in term of reward. This suggests that consideration given by the company to the Malaysian executive is less. Such a situation also led to dissatisfaction among Malaysian expatriate executives. Social networks play an essential role in expatriate adjustment and job performance. Researchers have highlighted the concept of social network and explain that this help expatriate gains social support from host and home country nationals. This support helps them to adjust to the host country and improve their job performance.

Social life element includes food, shopping, banking, cost of living, entertainment/recreation and health care facilities (Zainol \& Aziz, 2010). Social life is essential with general adjustment; thus, expatriates facing different types of adjustments such as food, shopping, etc. (Zhuang, Wu, \& Wen, 2013). Previous studies of expatriates show that these individual basic needs influence to general adjustment 
of expatriates. Expatriates need to make an adjustment of social life in the host country. To access all the elements in the host country is different while in the home country. Social life is important in daily needs. If expatriates can accept the differences, the expatriates tend to stay longer in the organisation. Otherwise, expatriates did not satisfied or unable to enjoy the social life in abroad could early return to the home country. Cost of living in a host country is exciting, but, it can also be a challenge if not capable of sustaining living comfortably. Expatriates in abroad who are followed similar daily life in the home country, especially custom and living environment will not be having difficulties to adjustment with the home country. Thus, expatriates can reduce the intention to leave and increase the retention in the organisation. However, the difficulties in adapting to the new environment will lead the expatriate to leave the organisation or early return to the home country.

The study revealed the most psychological comfort among expatriates which are interaction, living condition, reward and social life. The psychological comfort needs to take into account, in conjunction to reduce the propensity to leave, which eventually may lead to brain drain (Jauhar \& Yusoff, 2011), seeing that the brain drain of our Malaysian professionals will continue to affect Malaysia's transformation. Malaysia, as a developed nation is seeking more professional and skilled workers. In line with Malaysia strategies to build the human capital that can help the country achieve its aspiration of becoming a developed nation and smart communities by 2050.

\subsection{Conclusion \& Recommendations}

This study contributes to the understanding of the psychological distress of Malaysian professional during their assignment in the host country. It was found four components are influencing the psychological distress, namely interaction adjustment, living environment, reward and social life. The selection of an expatriate for the international assignment does involve not only technical expertise but also the ability of an individual to adjust and accept a new normal in the host country. Hence, international companies must get support from the workers and host country nationals, especially the professionals who are assigned to work overseas. Malaysia is one developing country which is not spared from this phenomenon that is detrimental to the economy.

Psychological distress concerns the needs, which are more complex and produced by environments and lifestyle to which the individual has to adapt. The needs of psychological comfort will affect the whole life of the expatriates. From that, it could be seen whether expatriates are able to adapt to the new environment or not. Psychological distress also will affect the working environment. They still need psychological comfort adjustment while working. Hence, expatriates could retain or leave in the organisation. It is challenging to retain Malaysians who are skilled and professional if there are better remuneration and reward offered by other companies overseas. Although it will lead to the loss of Malaysia's talents and affect the economy, they will be bringing back priceless experience when they return home.

Nevertheless, the highest demand for Malaysian professionals working abroad can cause Malaysia to face a shortage of professionals within the country. Malaysia is facing a talent crisis because of a lack of skilled and knowledgeable professionals. The study needs to focus more on the strength, skill and talent of the professionals. This will create a better workplace environment and also well-being. The improvement of psychological distress has an impact on individual, society, economy and country, thus enables the country to be a developed nation. All parties should work together to provide better living conditions and improve the quality of life. The research also helps to propose an effective preventive intervention towards a better workplace for Malaysian professionals.

\section{Acknowledgement}

The authors would like to thank Universiti Teknologi MARA and Ministry of High Education (MOHE), Malaysia, for funding this research (FRGS/1/2018/SSI08/UiTM/02/1. The authors are also thankful to all organisations and individuals who supported to this research.

\section{References}

Black, J.S. (1988), Work Role Transitions: A Study of American Expatriate Managers in Japan. Journal of International Business Studies, $19(2), 277$ - 294.

Barna, L. M. (1983). The stress factor in intercultural relations. In D. Landis \& R. W. Brislin (Eds.), Handbook of intercultural training (Vol. 2): $19-49$.

Caligiuri, P. M., Hyland, M. M., Joshi, A., \& Bross, A. S. (1998). Testing a theoretical model for examining the relationship between family adjustment and expatriates' work adjustment. Journal of Applied Psychology, 83(4), 598-614.

Davies, S., Kraeh, A. \& Froese, F. (2014) Burden or support? The influence of partner nationality on expatriate cross-cultural adjustment. Journal of Global Mobility. 3(2), 169-182.

Fish, A., \& Fish, A. (2006). Assisting cross-border manager adjustment interventions.Personel Review. 34(2). https://doi.org/10.1108/00483480510579448. 225-245.

Fisher, K. (2015). Pioneers across war zones: The lived acculturation experiences of US female military expatriates. International Journal of Intercultural Relations. https://doi.org/10.1016/j.ijintrel.2015.05.005. 265-277.

Fitzpatrick, F. (2019). Coping with authoritarianism in international relocation. Critical Perspectives on International Business. $1742-4043$.

Fitzpatrick, F., \& Fitzpatrick, F. (2017). Taking the "culture " out of "culture shock" - a critical review of literature on cross-cultural adjustment in international relocation Critical Perspectives on International Business. https://doi.org/10.1108/cpoib-01-2017-0008. 1742-2043 
Fitzpatrick, F., \& Fitzpatrick, F. (2019). Coping with authoritarianism in international relocation A case of cross-cultural adjustment research in context - Cuba. Critical Perspectives on International Review. https://doi.org/10.1108/cpoib-01-2018-0003. 1742-2043

Froese, F. J., \& Peltokorpi, V. (2011). Cultural distance and expatriate job satisfaction. International Journal of Intercultural Relations, 35(1), 49-60. https://doi.org/10.1016/j.jijintrel.2010.10.002

Halim, H., Bakar, H. A., \& Mohamad, B. (2019). Expatriation in Malaysia : Predictors of Cross-Cultural Adjustment among Hotel Expatriates. International Journal of Supply Chain Management. 8(1), 664-675.

Horwitz, F. (2017). International HRM in South African multinational companies. Journal of International Management, 23(2), https://doi.org/10.1016/j.intman.2017.01.005. 208-222.

Jauhar, J. \& Yusoff, Y. M. (2011). Brain Drain: Propensity to Leave by Malaysian Professionals. International Journal of Innovation, Management and Technology, 2(2). $119-122$.

Leung, M., Chan, I. Y. S. \& Cooper, C. L. (2019) Stress Management in the Construction Industry. Retrieved 29 January 2019 from https://onlinelibrary.wiley.com/doi/book/10.1002/9781118456361

Lin, P., Robbins, N., \& Lin, P. (2019). Research of Media Industry's Expatriates ' Cross-Culture Adjustment on the Job Involvement and Work Stress : The Impact of Relatedness. Realities in a Kaleidoscope. 64. 120-129

Moran R.T., Harris P.R., \& Moran S.V. (2011), Managing Cultural Differences: Global Leadership Strategies for the 21st Century. Oxford. UK.

Naithani, P., \& Jha, A. N. (2014). Challenges Faced by Expatriate Workers in Gulf Cooperation Council Countries. International Journal of Business and Management, 5(1), https://doi.org/10.5539/ijbm.v5n1p98. 98-104.

Okpara, J. O. (2016) Cross-cultural adjustment of expatriate: Exploring factors influencing adjustment of expatriates in Nigeria. International Journal of Cross Cultural Management, 1-22.

Pinto, S., Fumincelli, L., Mazzo, A., Caldeira, S., \& Martins, J. C. (2017). Comfort, well-being and quality of life: Discussion of the differences and similarities among the concepts. Porto Biomedical Journal, 2(1), 6-12.

Peltokorpi, V., \& Ramaswami, A. (2019). Abusive supervision and subordinates ' physical and mental health : the effects of job satisfaction and power distance orientation. The International Journal of Human Resource Management, https://doi.org/10.1080/09585192.2018.1511617. 1-27.

Presbitero, A., \& Quita, C. (2017). Expatriate career intentions : Links to career adaptability and cultural intelligence. 98, 118-126.

Rasool, A., Jundong, H., \& Sohail, M. T., (2017). Relationship of Intrinsic and Extrinsic Rewards on Job Motivation and Job Satisfaction of Expatriates in China. Journal of Applied Sciences, 17: 116-125.

Selmer, J., \& Lauring, J. (2011). Host country language ability and expatriate adjustment: the moderating effect of language difficulty. The International Journal of Human Resource Management, 26(3), 401-420.

Stroppa, C., \& Spieß, E. (2011). International assignments: The role of social support and personal initiative. International Journal of Intercultural Relations, 35(2), https://doi.org/10.1016/j.jijntrel.2010.09.008. 234-245.

Tung, R. L. (1998). A contingency framework of selection and training of expatriates revisited. Human Resource Management Review, 8(1), 23-37.

Vlaj, D., Caputo, A., Marzi, G., \& Dabi, M. (2019). Expatriates managers ' cultural intelligence as promoter of knowledge transfer in multinational companies. 94, https://doi.org/10.1016/j.jbusres.2018.01.033.367-377.

Vianen, V., Pater, I.D., E., Kristof-Brown, A. L., \& Johnson, E. C. (2004) Fitting in: Surface- and Deep-Level Cultural Differences and Expatriates' Adjustment. Academy of Management Journal, 47(5), 697-709.

Wahab, M. A. (2014). The Occurrence of Brain Drain in Malaysia : Perceptions on to Work or not to Work Overseas in the Future. 5(5), 480-489.

Zainol, H., Isa, H. M., Alauddin, K., \& Derus, M. M. (2016). General Adjustment Influence Factor of Malaysian Construction Expatriates Executives Abroad. $00012,10-$ 15.

Zainol, H. \& Aziz, A. R. A. (2010) Personal Adjustment for expatriate Academy of Management Journal, 47(5), 697-709.

Zainordin, N., Tan, C., \& Mei, Y. (2015). An Insight of Sustainable Development Professional in Malaysia A Study Among Construction. 2(2), 56-64.

Zhuang, W.-L., Wu, M., \& Wen, S.-L. (2013). Relationship of mentoring functions to expatriate adjustments: comparing home country mentorship and host country mentorship. The International Journal of Human Resource Management, 24(1), 35-49. 